Article

\title{
Analytical Expression of Parabolic Trough Solar Collector Performance
}

\author{
Evangelos Bellos* (i) and Christos Tzivanidis
}

Thermal Department, School of Mechanical Engineering, National Technical University of Athens, Zografou, Heroon Polytechniou 9, 15780 Athens, Greece; ctzivan@central.ntua.gr

* Correspondence: bellose@central.ntua.gr; Tel.: +30-21-0772-2340

Received: 7 February 2018; Accepted: 27 February 2018; Published: 2 March 2018

\begin{abstract}
The parabolic trough collector is one of the most developed solar concentrating technologies for medium and high temperatures (up to $800 \mathrm{~K}$ ). This solar technology is applied in many applications and so its investigation is common. The objective of this study is to develop analytical expressions for the determination of the thermal performance of parabolic trough collectors. The non-linear equations of the energy balances in the parabolic trough collector device are simplified using suitable assumptions. The final equation set includes all the possible parameters which influence the system performance and it can be solved directly without computational cost. This model is validated using experimental literature results. Moreover, the developed model is tested using another model written in Engineering Equation Solver under different operating conditions. The impact of the inlet fluid temperature, flow rate, ambient temperature, solar beam irradiation, and the heat transfer coefficient between cover and ambient are the investigated parameters for testing the model accuracy. According to the final results, the thermal efficiency can be found with high accuracy; the deviations are found to be up to $0.2 \%$ in the majority of the examined cases. Thus, the results of this work can be used for the quick and accurate thermal analysis of parabolic trough collector. Moreover, the analytical expressions give the possibility for optimizing solar thermal systems driven by parabolic trough collectors with lower computational cost.
\end{abstract}

Keywords: parabolic trough collector; thermal efficiency; analytical expression; solar thermal; optimization tool

\section{Introduction}

Solar energy is one of the most promising energy sources for achieving sustainability and facing important issues as global warming, fossil fuel depletion and the increasing price of electricity $[1,2]$. Concentrating solar collectors are suitable technologies for producing useful heat at medium and high temperatures, up to $800 \mathrm{~K}$, with a satisfying efficiency. The most common technologies are parabolic trough collector (PTC), linear Fresnel reflector, solar dish, and solar tower [3]. Among these systems, parabolic trough collector is one of the most mature technologies and it has been widely studied and used the last decades [4].

The thermal analysis of PTC is an important issue which has been examined by numerous researchers in the literature. There are many experimental studies, as well as theoretical studies for estimating its performance. The theoretical studies are separated into two categories; the computational fluid dynamic studies (CFD) and studies with developed thermal models. In all these categories, there is a great number of studies which investigate a great variety of PTCs. However, there is lack of studies which predict the performance of PTC in an analytical and direct way.

In the literature, there are many experimental studies for PTC which examine these collectors with water or thermal oil. These studies try to determine the thermal and optical performance of the 
collector, while important issues about the operation of the PTC are highlighted. The most significant experimental study has been performed by Dudley et al. [5] about the LS-2 PTC. This study has been used in a great range of future studies for validation purposes. Recently, a PTC was investigated experimentally under the IEC 62862-3-2 standard by Sallaberry et al. [6]. Another important experimental study has been conducted by Wang et al. [7]. They applied an on-site test method for thermal and optical performances of the parabolic trough loop. Moreover, it is worthy to state about the experimental study of Chafie et al. [8] where a PTC was examined energetically and exergetically. They found the daily energy efficiency to be ranged from $19.7 \%$ to $52.6 \%$, while the exergy from $8.51 \%$ to $16.34 \%$.

The next part of studies in the literature regards the CFD studies where the Navier-Stokes equations are solved with the proper tool or codes. These studies put emphasis on the detailed and precise calculations inside the flow of the absorber tube. Wu et al. [9] performed a study about a PTC using a three-dimensional numerical model. They used the solver FLUENT and inserted a non-uniform heat flux distribution in the absorber periphery. Important studies have been performed by Mwesigye et al. [10-12] with a similar methodology. They optimized the PTC by minimizing the entropy generation in the collector. On the other hand, Ghasemi et al. $[13,14]$ used the FLUENT tool with a uniform heat flux over the absorber tube. Tzivanidis et al. [15] and Bellos et al. [16,17] have used SolidWorks Flow Simulation for simulating the performance of PTC. This software includes modules for thermal and optical analysis. They examined different working fluids for various operating conditions under non-uniform heat flux distribution over the absorber.

The next part of the literature studies about the PTC performance includes numerous studies with thermal models. These models solve non-linear equations with a code or a solver and finally, the performance of the collector is calculated. A usual thermal model has been suggested by Forristall [18] and it has been programmed in Engineering Equation Solver (EES). This model has been used widely for validation purposes by many researchers. Other studies with models in EES have been performed by Bellos et al. [19-25], where different working fluids have been examined in PTC and the collector has been examined energetically and exergetically. Moreover, a detailed model for the simulation of PTC in EES has been given by Kalogirou et al. [26] for evacuated and non-evacuated tube receivers. Similar models have been also found in Refs. $[27,28]$. These models in EES are mainly based on the energy balances on the absorber. The idea for separating the tube into two parts (upper and down) has been examined by Padilla et al. [29] and Cheng et al. [30]. This idea takes into account that the upper part of the receiver radiates with the sky while the down with the reflector or the ambient. In an interesting comparative study, Liang et al. [31] found that the 1-D models give higher accuracy than the 3-D model, compared to the experimental results. They stated that there are numerous assumptions in the 3-D models which increase the errors and so they are not so reliable as the simpler models.

Moreover, it is important to state that there is a part of the literature studies which investigates the PTC performance with analytical approaches. The first part of these studies investigates the optical performance of the PTC with various analytical ways. Jeter [32] presented a semifinite analytical formulation about the concentrated heat flux over the absorber. This modeling was a non-uniform heat flux modeling and it can predict the optical efficiency of the collector. Khanna et al. [33] also developed an analytical modeling for the optical efficiency of a PTC. They have taken into account the optical errors due to the sun shape, tube bending, and concentrator errors. Fraidenraich et al. [34] developed a detailed analytical modeling for the performance of a direct steam generation power plant. The examined the solar collector, as well as other devices of the power plant. They developed analytical expressions which have been validated with other literature results.

Eck et al. [35] compared different thermal models for a PTC. More specifically, they examined an analytical modeling of Ref [36], which predicts the receiver temperature distribution in an analytical way. They also studied the numerical model of Sandia reports [5] and a developed finite element method model (FEM). They found that all the models lead to reliable results, with the FEM to be better for the determination of the receiver temperature, and the thermal model to be a good choice for 
thermal performance calculations. In the literature, there are also important review studies [37-39] which summarize and discuss the developed methodologies for the performance estimation of PTC. The previous literature review indicates that there are numerous literature studies which analyze the performance of PTC. However, the studies which investigate the thermal performance of PTC with an analytical approach are restricted and seldom in the literature. Thus, this study suggests a simple modeling with analytical equations for the accurate and easy prediction of PTC performance. This modeling does not have the requirement of a solver or a programming code and the model equations can be solved directly without any computational cost. All the main parameters of the PTC, its dimension, optical and thermal properties, and the operating conditions, are inserted in the present modeling. This thermal model is validated and so its accuracy is tested for different operating scenarios.

\section{Material and Methods}

\subsection{Mathematical Modeling}

The present modeling is based on the modeling of Refs [19-25] where the basic energy balances on the receiver are performed. The equations of the present modeling are simpler expressions of the modeling of the Refs [19-25] which had been used in EES program. Figure 1 depicts a typical parabolic trough collector.

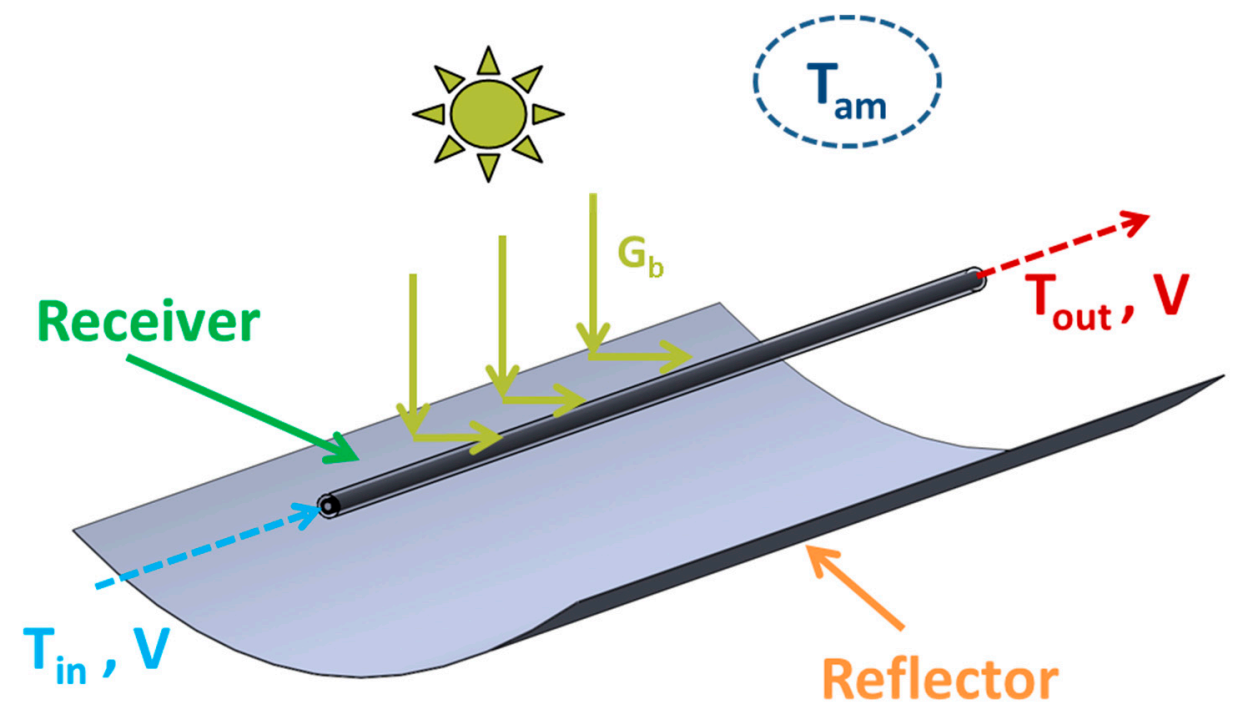

Figure 1. A typical parabolic trough collector.

\subsubsection{Model Assumptions}

The following assumptions are applied in the present modeling:

- The PTC is assumed to be in steady-state conditions.

- There are no contact thermal losses.

- The receiver is an evacuated tube and the heat convection losses between absorber and cover are neglected.

- There is uniform heat flux over the absorber.

- The receiver temperature does not have great variation along the tube because the collector has a reasonable length $(\sim 10 \mathrm{~m})$.

- The solar collector radiates thermally to the ambient.

- There is no great difference between cover and ambient temperature level.

- There is no great difference between the receiver and fluid temperature level. 
- The flow is fully developed and it can be characterized by a constant heat transfer coefficient along the tube.

- This model needs the knowledge of the fluid thermal properties, as well as of the heat transfer coefficient.

- All the thermal properties, as well as the receiver emittance, can be estimated for the temperature level of the inlet temperature.

\subsubsection{Steps of the Developed Modeling}

The present modeling can be separated into five steps.

\section{STEP 1}

The thermal losses from the cover to the ambient are radiation and convection losses, and they can be written as below. At this point, it is important to state that the contact thermal losses are neglected.

$$
Q_{\text {loss }}=A_{c o} \times \varepsilon_{c} \times \sigma \times\left(T_{c}^{4}-T_{a m}^{4}\right)+A_{c o} \times h_{o u t} \times\left(T_{c}-T_{a m}\right)
$$

The cover temperature is assumed to be close to the ambient temperature because of the existence of an evacuated tube collector. Thus, using Taylor series, it can be written:

$$
T_{c}^{4}-T_{a m}^{4} \approx 4 \times T_{a m}^{3} \times\left(T_{c}-T_{a m}\right)
$$

Equation (2) is an important assumption of this work and its validity is tested by the comparisons between this and other models, which are given in Section 3.

Using Equations (1) and (2), it can be written:

$$
Q_{\text {loss }}=\left[A_{c o} \times \varepsilon_{c} \times \sigma \times 4 \times T_{a m}^{3}+A_{c o} \times h_{\text {out }}\right] \times\left(T_{c}-T_{a m}\right)
$$

or

$$
Q_{\text {loss }}=K_{1} \times\left(T_{c}-T_{a m}\right)
$$

with

$$
K_{1}=A_{c o} \times \varepsilon_{c} \times \sigma \times 4 \times T_{a m}^{3}+A_{c o} \times h_{o u t}
$$

\section{STEP 2}

The present model is developed for steady-state conditions. In this case, the thermal losses of the absorber to the cover are equal to the thermal losses of the cover to the ambient.

The thermal losses of the absorber to the cover are only radiation losses because of the vacuum between the absorber and the cover (there are no convection thermal losses):

$$
Q_{\text {loss }}=A_{r o} \times \varepsilon_{r}^{*} \times \sigma \times\left(T_{r}^{4}-T_{c}^{4}\right)
$$

with

$$
\varepsilon_{\mathrm{r}}^{*}=\left[\frac{1}{\varepsilon_{\mathrm{r}}}+\frac{1-\varepsilon_{\mathrm{c}}}{\varepsilon_{\mathrm{c}}} \times \frac{\mathrm{A}_{\mathrm{ro}}}{\mathrm{A}_{\mathrm{ci}}}\right]^{-1}
$$

The Equation (6) can be written as below. It is important to state that the cover has been assumed to radiate to the ambient conditions.

$$
Q_{\text {loss }}=A_{r o} \times \varepsilon_{r}^{*} \times \sigma \times\left(T_{r}^{4}-T_{a m}^{4}\right)-A_{r o} \times \varepsilon_{r}^{*} \times \sigma \times\left(T_{c}^{4}-T_{a m}^{4}\right)
$$

Using Equations (2) and (4), it can be written: 


$$
T_{c}^{4}-T_{a m}^{4}=\frac{4 \times T_{a m}^{3}}{K_{1}} \times Q_{\text {loss }}
$$

Using Equations (8) and (9), it can be said:

$$
Q_{\text {loss }}=A_{r o} \times \varepsilon_{r}^{*} \times \sigma \times\left(T_{r}^{4}-T_{a m}^{4}\right) \times\left[1+\frac{4 \times T_{a m}^{3} \times A_{r o} \times \varepsilon_{r}^{*} \times \sigma}{K_{1}}\right]^{-1}
$$

or

$$
Q_{\text {loss }}=K_{2} \times\left(T_{r}^{4}-T_{a m}^{4}\right)
$$

with

$$
K_{2}=A_{r o} \times \varepsilon_{r}^{*} \times \sigma \times\left[1+\frac{4 \times T_{a m}^{3} \times A_{r o} \times \varepsilon_{r}^{*} \times \sigma}{K_{1}}\right]^{-1}
$$

STEP 3

The useful heat can be calculated using the energy balance in the fluid volume:

$$
Q_{u}=m \times c_{p} \times\left(T_{\text {out }}-T_{\text {in }}\right)
$$

Furthermore, it can be calculated using the heat transfer from the receiver to the fluid:

$$
Q_{u}=A_{r i} \times h \times\left(T_{r}-T_{f m}\right)
$$

At this point, it can be said that the heat transfer coefficient in the flow has been assumed to be the same along the absorber tube.

The mean fluid temperature can be estimated as:

$$
T_{f m}=\frac{T_{\text {in }}+T_{\text {out }}}{2}
$$

Using the Equations (13)-(15), it can be written:

$$
Q_{u}=\left[\frac{1}{A_{r i} \times h}+\frac{1}{2 \times m \times c_{p}}\right]^{-1} \times\left(T_{r}-T_{i n}\right)
$$

or

$$
Q_{u}=K_{3} \times\left(T_{r}-T_{\text {in }}\right)
$$

with

$$
K_{3}=\left[\frac{1}{A_{r i} \times h}+\frac{1}{2 \times m \times c_{p}}\right]^{-1}
$$

STEP 4

The goal of this step is to simplify the Equation (11). The following transformation of the Equation (11) can be written:

$$
Q_{\text {loss }}=K_{2} \times\left(T_{r}^{4}-T_{i n}^{4}\right)+K_{2} \times\left(T_{i n}^{4}-T_{a m}^{4}\right)
$$

Generally, the temperature difference between receiver and fluid is not so high. Thus, using Taylor series, it can be written:

$$
T_{r}^{4}-T_{\text {in }}^{4} \approx 4 \times T_{\text {in }}^{3} \times\left(T_{r}-T_{\text {in }}\right)
$$

Using Equations (17) and (20), it can be written: 


$$
T_{r}^{4}-T_{i n}^{4} \approx \frac{4 \times T_{i n}^{3}}{K_{3}} \times Q_{u}
$$

Using Equations (19) and (21), it can be said:

$$
Q_{\text {loss }}=\frac{4 \times T_{i n}^{3} \times K_{2}}{K_{3}} \times Q_{u}+K_{2} \times\left(T_{i n}^{4}-T_{a m}^{4}\right)
$$

\section{STEP 5}

The energy balance in the absorber indicates that the absorbed energy is converted into useful heat and to thermal losses. At this point, a uniform heat flux over the absorber is assumed. The absorbed energy is equal to the optical efficiency multiplied by the direct beam solar irradiation. Thus, it can be written:

$$
\eta_{\text {opt }} \times Q_{s}=Q_{u}+Q_{\text {loss }}
$$

Using Equations (22) and (23), it can be written:

$$
Q_{u}=\left[\eta_{o p t} \times Q_{s}-K_{2} \times\left(T_{i n}^{4}-T_{a m}^{4}\right)\right] \times\left[1+\frac{4 \times T_{i n}^{3} \times K_{2}}{K_{3}}\right]^{-1}
$$

or

$$
Q_{u}=K_{4} \times Q_{s}-K_{5} \times\left(T_{i n}^{4}-T_{a m}^{4}\right)
$$

with

$$
K_{4}=\eta_{o p t} \times\left[1+\frac{4 \times T_{\text {in }}^{3} \times K_{2}}{K_{3}}\right]^{-1}
$$

and

$$
K_{5}=K_{2} \times\left[1+\frac{4 \times T_{i n}^{3} \times K_{2}}{K_{3}}\right]^{-1}
$$

\subsubsection{Other Parameter Calculations}

The thermal efficiency of the solar collector $\left(\eta_{t h}\right)$ can be calculated as:

$$
\eta_{t h}=K_{4}-K_{5} \times \frac{\left(T_{i n}^{4}-T_{a m}^{4}\right)}{A_{a} \times G_{b}}
$$

Using Equations (23) and (25), the thermal losses $\left(Q_{\text {loss }}\right)$ can be written as:

$$
Q_{\text {loss }}=\left(\eta_{\text {opt }}-K_{4}\right) \times Q_{s}+K_{5} \times\left(T_{i n}^{4}-T_{a m}^{4}\right)
$$

Using Equations (17) and (25), the receiver temperature $\left(T_{r}\right)$ can be written as:

$$
T_{r}=T_{i n}+\frac{K_{4}}{K_{3}} \times Q_{s}-\frac{K_{5}}{K_{3}} \times\left(T_{i n}^{4}-T_{a m}^{4}\right)
$$

Using Equations (4) and (25), the cover temperature $\left(T_{c}\right)$ can be written as:

$$
T_{c}=T_{a m}+\frac{\eta_{o p t}-K_{4}}{K_{1}} \times Q_{s}+\frac{K_{5}}{K_{1}} \times\left(T_{i n}^{4}-T_{a m}^{4}\right)
$$

Using Equations (13) and (25), the fluid outlet temperature $\left(T_{\text {out }}\right)$ can be written as:

$$
T_{\text {out }}=T_{\text {in }}+\frac{K_{4}}{m \times c_{p}} \times Q_{s}-\frac{K_{5}}{m \times c_{p}} \times\left(T_{i n}^{4}-T_{a m}^{4}\right)
$$


Using Equations (15) and (32), the mean fluid temperature $\left(T_{f m}\right)$ can be written as:

$$
T_{f m}=T_{i n}+\frac{K_{4}}{2 \times m \times c_{p}} \times Q_{s}-\frac{K_{5}}{2 \times m \times c_{p}} \times\left(T_{i n}^{4}-T_{a m}^{4}\right)
$$

\subsubsection{Extra Equations for the Developed Model}

This model needs some extra equation in order to be complete. These equations are associated with the calculation of some parameters which can be used as inputs in the present modeling.

The optical efficiency $\left(\eta_{\text {opt }}\right)$ can be calculated as the product of the incident angle modifier $K(\theta)$ to the maximum optical efficiency $\left(\eta_{\text {opt }, \text { max }}\right)$, which is obtained for zero incident angle:

$$
\eta_{\text {opt }}(\theta)=K(\theta) \times \eta_{o p t, m a x}
$$

The maximum optical efficiency can be calculated as a product of various parameters which are associated with the collector:

$$
\eta_{o p t, \max }=\rho_{c} \times \gamma \times \tau \times \alpha
$$

More specifically, the absorber absorbance $(\alpha)$, concentrator reflectance $\left(\rho_{c}\right)$, cover transmittance $(\tau)$, and intercept factor $(\gamma)$ are used for the calculation of the maximum optical efficiency. It is important to state that the intercept factor is an important design parameter which is depended on the geometrical design and the possible design errors. It practically shows the percentage of the reflected solar irradiation which reaches to the receiver. The mass flow rate $(m)$ can be calculated using the volumetric flow rate $(V)$ and the density $(\rho)$ :

$$
m=\rho \times V
$$

The heat transfer coefficient between the fluid and the absorber $(h)$ can be calculated using the Nusselt number:

$$
h=\frac{N u \times k}{D_{r i}}
$$

The Nusselt number $(\mathrm{Nu})$ can be estimated using equations from the literature for internal flow in circular tubes.

For laminar flow [40]:

$$
N u=3.66+\frac{0.0667 \times \operatorname{Re} \times \operatorname{Pr} \times D_{r i} / L}{1+0.04 \times\left(\operatorname{Re} \times \operatorname{Pr} \times \frac{D_{r i}}{L}\right)^{\frac{2}{3}}}
$$

For turbulent flow (Dittus-Boelter equation) [40]:

$$
N u=0.023 \times \operatorname{Re}^{0.8} \times \operatorname{Pr}^{0.4}
$$

The Reynolds number $(R e)$ for the circular tube is defined as:

$$
\operatorname{Re}=\frac{4 \times m}{\pi \times D_{r i} \times \mu}
$$

The Reynolds number is a flow parameter which is used for the characterization of the flow. When it shows values lower than 2300, the flow is assumed to be laminar; otherwise, it can be assumed to be turbulent.

The Prandtl number $(P r)$ is defined as:

$$
\operatorname{Pr}=\frac{\mu \times c_{p}}{k}
$$


The Prandtl number is a dimensionless number which is used in heat transfer problems. This parameter is the ratio of the momentum diffusivity to the heat diffusivity.

\subsection{The Examined Parabolic Trough Collector (PTC)}

In this work, the module of LS-2 PTC is used, which is a PTC with evacuated tube receiver. This module has been widely used in studies in the literature. Table 1 gives the parameters of the present work. The data about the collector characteristics have been found in Refs $[5,18,27]$.

Table 1. Parameters of the study $[5,18,27]$.

\begin{tabular}{ccc}
\hline Parameter & Symbol & Value \\
\hline Width of the PTC & $W$ & $5.0 \mathrm{~m}$ \\
Length of the PTC & $L$ & $7.8 \mathrm{~m}$ \\
Focal distance of the PTC & $f$ & $1.71 \mathrm{~m}$ \\
Aperture of the PTC & $A_{a}$ & $39.0 \mathrm{~m}^{2}$ \\
Concentration ratio of the PTC & $C$ & 22.74 \\
Receiver inner diameter & $D_{r i}$ & $66 \times 10^{-3} \mathrm{~m}$ \\
Receiver outer diameter & $D_{r o}$ & $70 \times 10^{-3} \mathrm{~m}$ \\
Cover inner diameter & $D_{c i}$ & $109 \times 10^{-3} \mathrm{~m}$ \\
Cover outer diameter & $D_{c o}$ & $115 \times 10^{-3} \mathrm{~m}$ \\
Receiver inner surface & $A_{r i}$ & $1.617 \mathrm{~m}^{2}$ \\
Receiver outer surface & $A_{r o}$ & $1.715 \mathrm{~m}^{2}$ \\
Cover inner surface & $A_{c i}$ & $2.671 \mathrm{~m}^{2}$ \\
Cover outer surface & $A_{c o}$ & $2.818 \mathrm{~m}^{2}$ \\
Receiver emittance & $\varepsilon_{r}$ & 0.2 \\
Cover emittance & $\varepsilon_{c}$ & 0.9 \\
Absorber absorbance & $\alpha$ & 0.96 \\
Cover transmittance & $\tau$ & 0.95 \\
Concentrator reflectance & $\rho_{c}$ & 0.83 \\
Intercept factor & $\gamma$ & 0.99 \\
Incident angle & $K\left(\theta=0^{\circ}\right)$ & 1 \\
Incident angle modifier (zero incident angle) & $\theta$ & 0.9 \\
Maximum optical efficiency (zero incident angle) & $\eta_{o p t, m a x}$ & $75 \%$ \\
\hline & & \\
\hline
\end{tabular}

The working fluid is Syltherm 800 , which can operate up to $673 \mathrm{~K}$ with a safety [41]. It is important to state that the collector is investigated for zero incident angle in order to give the emphasis in the thermal analysis. The examined reflectance has been taken from the literature [22] and includes various optical losses due to the tracking system, dust in the concentrator, etc.

Table 2 includes the default values of the operating conditions parameters, as well as their investigated range. These value ranges have been examined in this work and it proved that the model is valid for these conditions. In every case, only one parameter is variable, while the other parameters have their default values, as they are given in Table 2. This technique aids to perform a suitable sensitivity analysis in the developed model and to check its behavior with different parameters.

Table 2. Operating conditions of the examined system.

\begin{tabular}{cccc}
\hline Parameter & Symbol & Value & Range \\
\hline Ambient temperature & $T_{a m}$ & $300 \mathrm{~K}$ & $280-320 \mathrm{~K}$ \\
Solar direct beam irradiation & $G_{b}$ & $1000 \mathrm{~W} / \mathrm{m}^{2}$ & $500-1000 \mathrm{~W} / \mathrm{m}^{2}$ \\
Heat transfer coefficient between cover and ambient & $h_{\text {out }}$ & $10 \mathrm{~W} / \mathrm{m}^{2} \mathrm{~K}$ & $5-20 \mathrm{~W} / \mathrm{m}^{2} \mathrm{~K}$ \\
Volumetric flow rate & $V$ & $0.025 \mathrm{~m}^{3} / \mathrm{s}$ & $0.001-0.004 \mathrm{~m}^{3} / \mathrm{s}$ \\
Inlet temperature & $T_{\text {in }}$ & $500 \mathrm{~K}$ & $300-650 \mathrm{~K}$ \\
\hline
\end{tabular}




\section{Results}

\subsection{Model Validation}

The first step in this work is the comparison of the developed model with the literature's experimental results. The results of Dudley et al. [5] about the LS-2 PTC are used in order to test if the suggested model gives reasonable results. Eight different cases are examined and are listed in Table 3. The outlet temperature and the thermal efficiency are compared in this table between the experimental results (EXP) of the Ref [5] and the results of the present model (MODEL). The mean deviation in the outlet temperature is found to be $0.06 \%$ and in the thermal efficiency, $1.16 \%$. These values are relatively low and so it is proved that the developed model is valid for various operating conditions.

Table 3. Validation of the presented model with literature experimental results.

\begin{tabular}{|c|c|c|c|c|c|c|c|c|c|c|}
\hline \multirow{2}{*}{ Cases } & \multirow{2}{*}{$\begin{array}{c}G_{b} \\
\left(W / m^{2}\right)\end{array}$} & \multirow{2}{*}{$\begin{array}{l}T_{a m} \\
(\mathrm{~K})\end{array}$} & \multirow{2}{*}{$\begin{array}{l}T_{\text {in }} \\
(\mathrm{K})\end{array}$} & \multirow{2}{*}{$\frac{V}{\left(\mathrm{~m}^{3} / \mathrm{s}\right)}$} & \multicolumn{3}{|c|}{$T_{\text {out }}(K)$} & \multicolumn{3}{|c|}{$\eta_{t h}(\%)$} \\
\hline & & & & & EXP & Model & Deviation & EXP & Model & Deviation \\
\hline 1 & 933.7 & 294.35 & 375.35 & 47.7 & 397.15 & 397.55 & $0.10 \%$ & 72.51 & 73.10 & $0.82 \%$ \\
\hline 2 & 968.2 & 295.55 & 424.15 & 47.8 & 446.45 & 446.97 & $0.12 \%$ & 70.90 & 72.21 & $1.85 \%$ \\
\hline 3 & 982.3 & 297.45 & 470.65 & 49.1 & 492.65 & 493.10 & $0.09 \%$ & 70.17 & 71.13 & $1.37 \%$ \\
\hline 4 & 909.5 & 299.45 & 523.85 & 54.7 & 542.55 & 542.48 & $0.01 \%$ & 70.25 & 69.33 & $1.31 \%$ \\
\hline 5 & 937.9 & 299.35 & 570.95 & 55.5 & 589.55 & 589.96 & $0.07 \%$ & 67.98 & 67.42 & $0.83 \%$ \\
\hline 6 & 880.6 & 301.95 & 572.15 & 55.6 & 590.35 & 589.90 & $0.08 \%$ & 68.92 & 67.07 & $2.69 \%$ \\
\hline 7 & 903.2 & 300.65 & 629.05 & 56.3 & 647.15 & 647.24 & $0.01 \%$ & 63.82 & 63.94 & $0.18 \%$ \\
\hline 8 & 920.9 & 304.25 & 652.65 & 56.8 & 671.15 & 671.23 & $0.01 \%$ & 62.34 & 62.48 & $0.23 \%$ \\
\hline Mean & - & - & - & - & - & - & $0.06 \%$ & - & - & $1.16 \%$ \\
\hline
\end{tabular}

\subsection{Parametric Investigation}

The parametric investigation of the solar collector is performed by comparing the obtained results with a developed model in EES. This model has been presented and validated in our previous literature studies [19-26], and is a suitable tool for this analysis. Practically, various sensitivity studies are performed in this section in order to check the model accuracy under different operating cases.

\subsubsection{The Impact of the Inlet Temperature on the Results}

The inlet temperature is the most important parameter in the present model and thus a detailed investigation is performed with this parameter. The inlet temperature ranges from 300 up to $650 \mathrm{~K}$, as has been stated in Table 2. The other parameters (flow rate, solar beam irradiation, etc.) are the default values of Table 2 .

Figures 2-5 depict the comparative results for the different inlet temperatures. Figure 2 illustrates the thermal efficiency, Figure 3 the thermal losses, Figure 4 the receiver temperature, and Figure 5 the cover temperature. In these figures, the results of the present modeling and of the literature modeling with the EES program are compared. Moreover, the deviation between these results is also given.

Generally, the results are extremely close to each other and so it is clearly proved that the suggested modeling is accurate. The deviations of the thermal efficiency (Figure 2) are up to $0.2 \%$. Moreover, the deviations in the receiver temperature (Figure 4) are up to $0.045 \%$. These results practically indicate that the EES modeling and analytical expression give the same results for the thermal efficiency and receiver temperature.

On the other hand, Figure 5 indicates that the cover temperature is calculated with a deviation up to $3.5 \%$, a small value but higher than the respective value for the receiver temperature in Figure 4 . The maximum deviation of the cover temperature is found at low inlet temperatures. The thermal losses of the collector are generally in acceptable deviation ranges but at low inlet temperatures, and there is a deviation up to $28 \%$. These high values are justified by the deviation of the cover temperature. However, the thermal losses in the low inlet temperatures are too low as heat values (in Watt) and so they do not have high impact on the thermal efficiency deviation (Figure 2). In other words, the 
possible deviations in the thermal losses of the collector at low temperatures do not lead to important deviations in the thermal efficiency (or in the useful heat production), which is the main goal of this modeling.

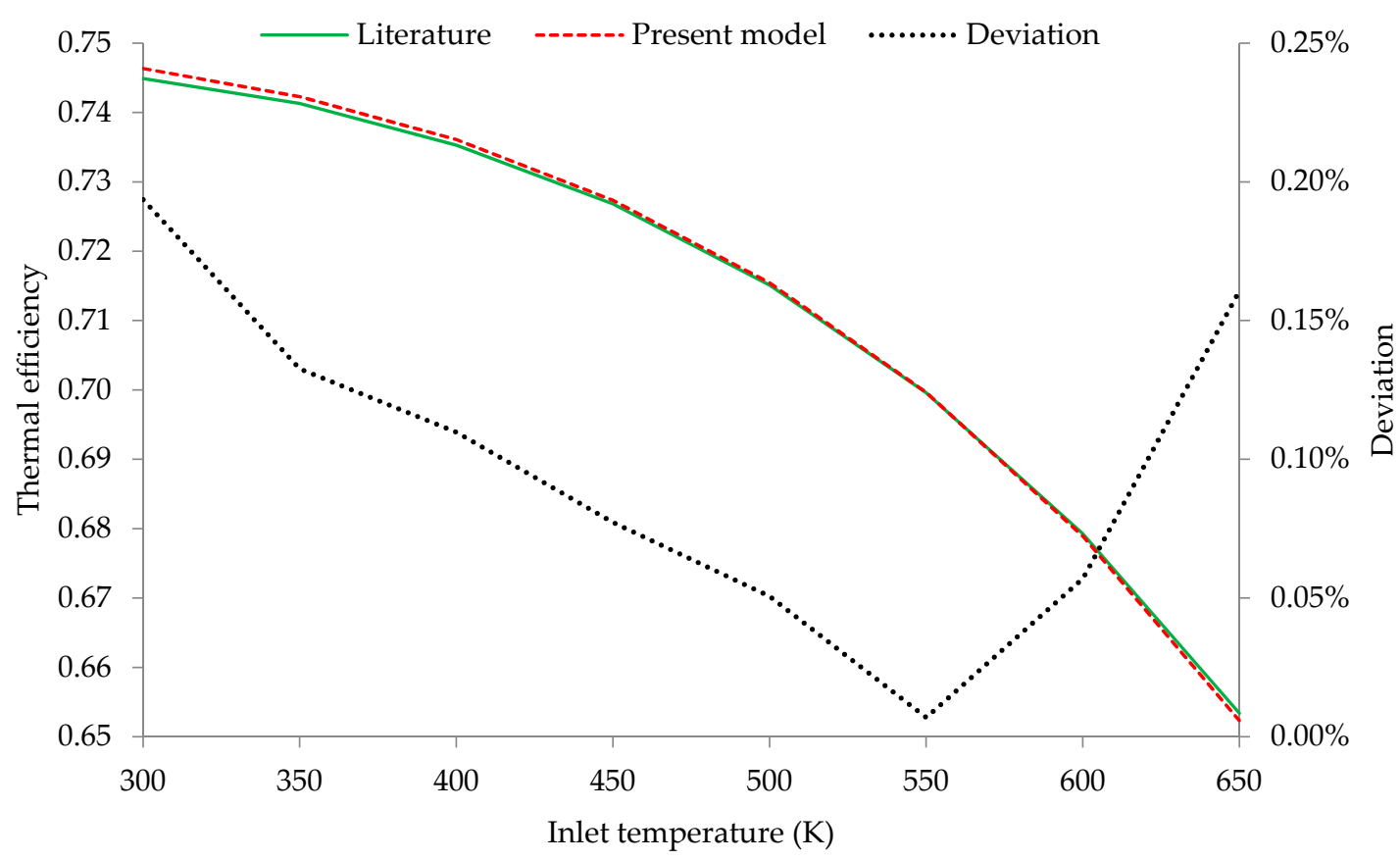

Figure 2. Thermal efficiency for different inlet temperatures-a comparison between the present model and the literature experimental model.

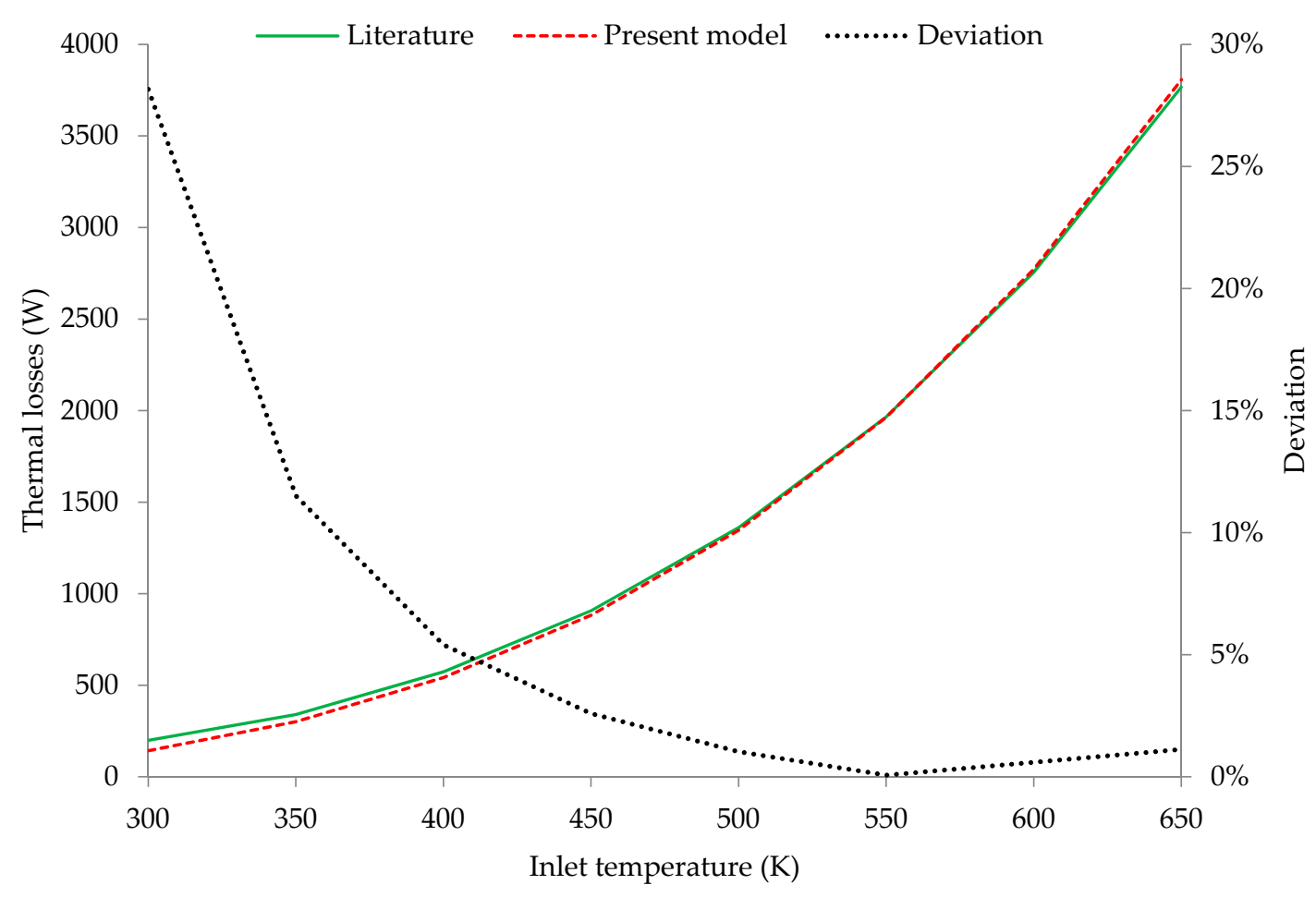

Figure 3. Thermal efficiency for different inlet temperatures-a comparison between the present model and the literature model. 


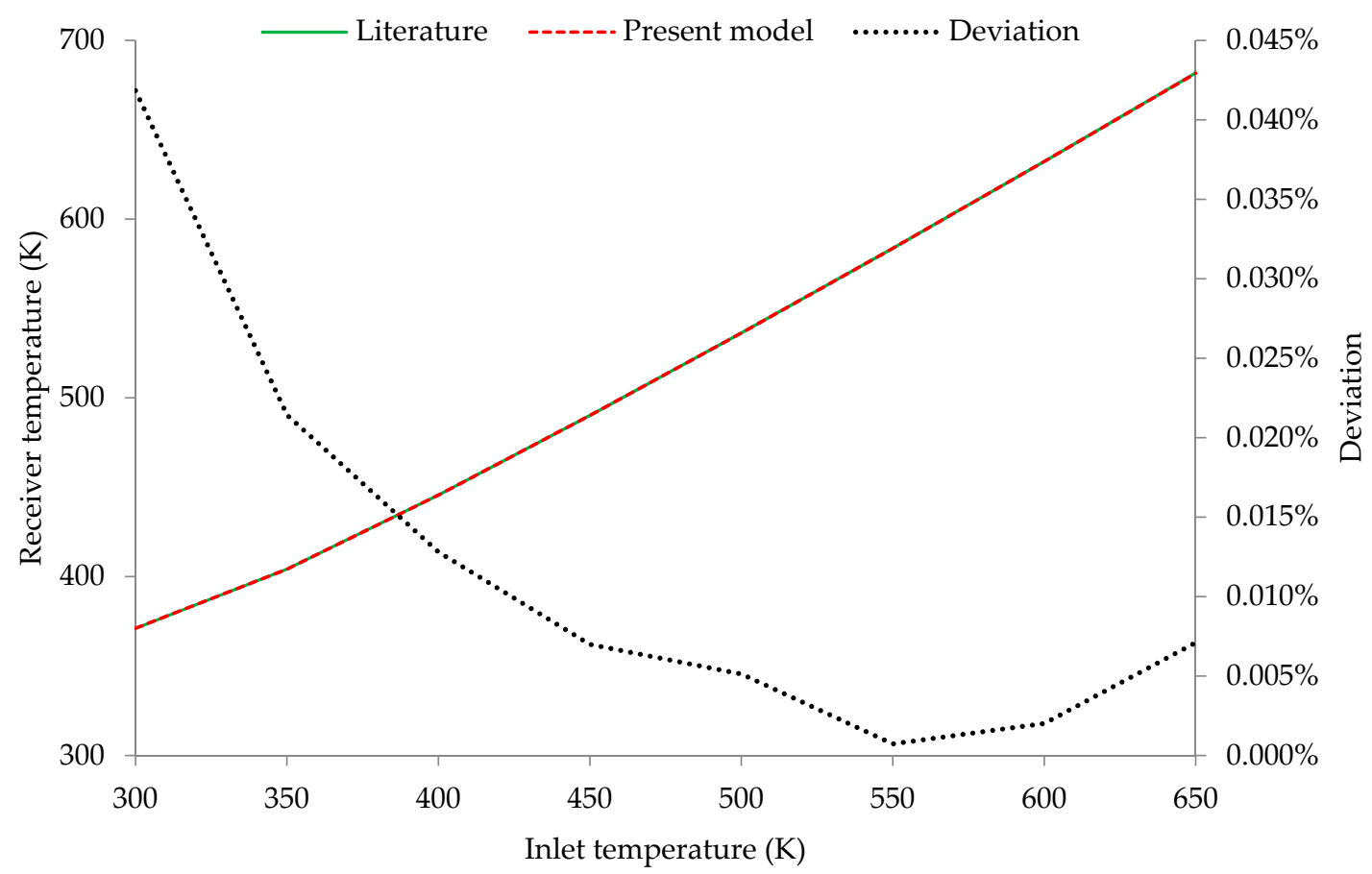

Figure 4. Thermal efficiency for different inlet temperatures-a comparison between the present model and the literature model.

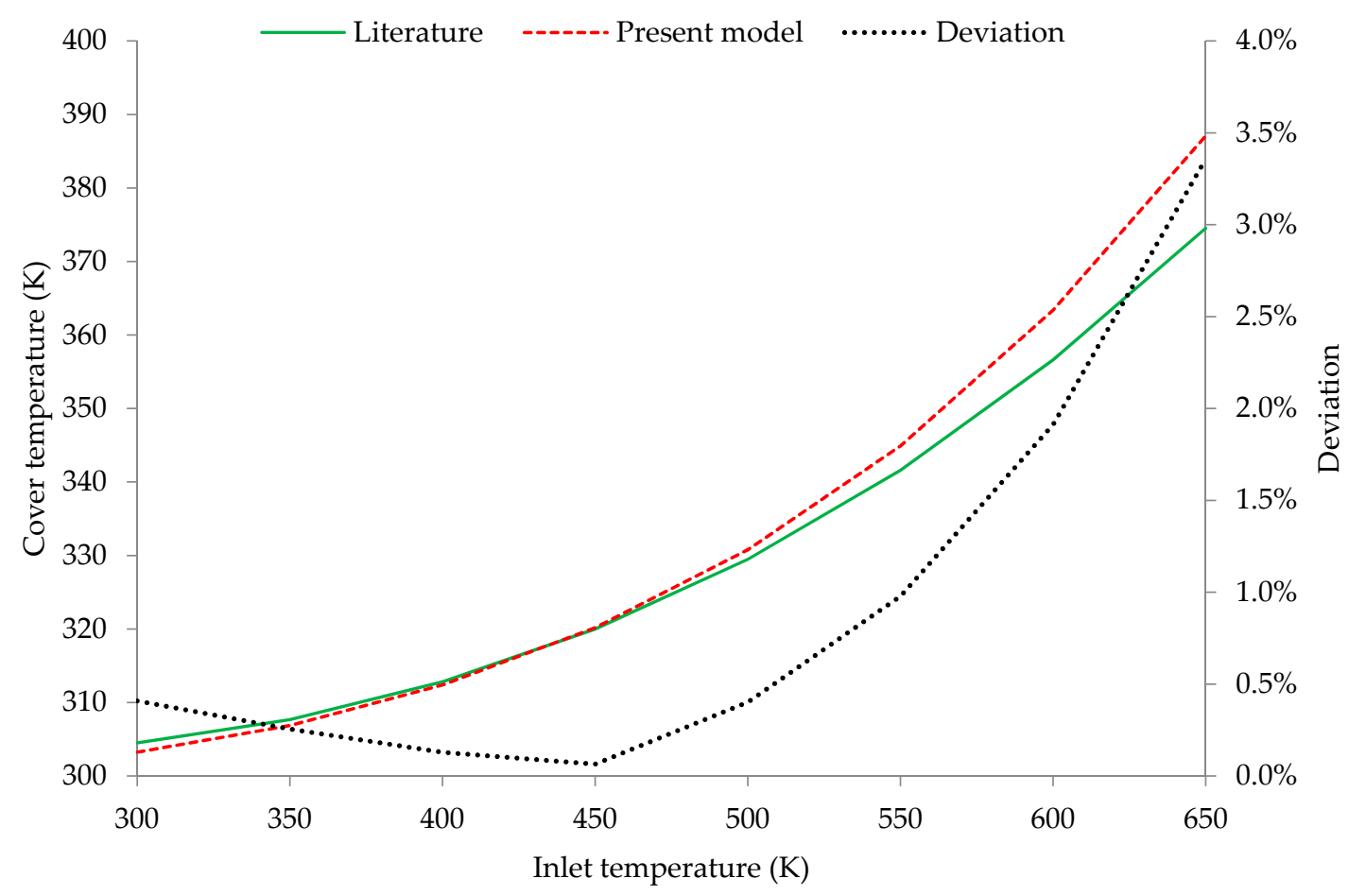

Figure 5. Thermal efficiency for different inlet temperatures-a comparison between the present model and the literature model. 


\subsubsection{The Impact of Various Parameters on the Results}

The impact of various parameters on the collector thermal performance is given in the Section 3.2.2. More specifically, Figures 6-9 illustrate the impact of the flow rate, ambient temperature, solar beam irradiation, and the heat transfer coefficient between cover and ambient on the collector performance.

Figure 6 indicates that the developed model is valid for all the examined flow rates from $0.001 \mathrm{~m}^{3} / \mathrm{s}$ up to $0.004 \mathrm{~m}^{3} / \mathrm{s}$. The maximum deviation is about $0.5 \%$ and is observed at low flow rates. Figure 7 shows that the impact of the ambient temperature on the model validity is extremely low. The deviations are around $0.05 \%$, which are extremely low values. It is essential to state that the abrupt change in the deviation is very small as a value (about $0.09 \%$ ) and does not influence the model validity. Moreover, Figure 8 indicates that the model is valid for all the examined solar beam irradiation levels, with the deviations to be up to $0.1 \%$. Lastly, Figure 9 proves that the model is also valid for different values of the heat transfer coefficient between the cover and ambient with deviations up to $0.06 \%$. The previous results clearly prove that the model is reliable for all the examined operating conditions.

At this point, it is important to discuss the impact of the examined parameters on the thermal performance. First of all, it must be said that higher the inlet temperature leads to lower thermal efficiency. This parameter has been an important impact on the efficiency, as Figure 2 indicates. Higher flow rate leads to greater performance (Figure 6), but the increase is not so important especially after the value of $0.0025 \mathrm{~m}^{3} / \mathrm{s}$. Higher ambient temperature increases the performance, as Figure 7 illustrates, but the increase seems to be extremely low. The increase of the solar irradiation is able to enhance the collector thermal performance according to the results of Figure 8. Figure 9 indicates that the impact of the heat transfer coefficient between cover and ambient is practically negligible to the thermal efficiency.

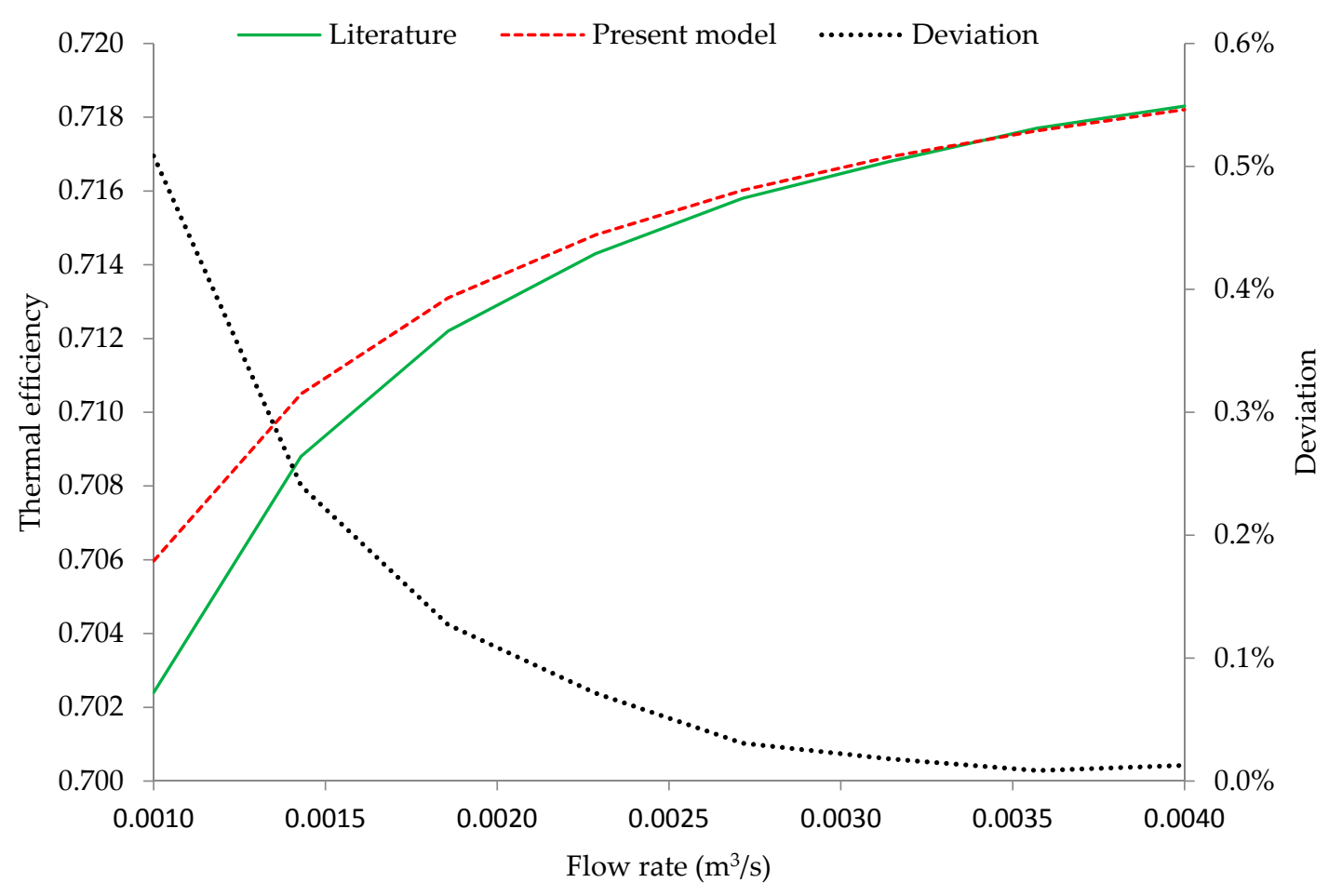

Figure 6. The impact of the flow rate on the model results. 


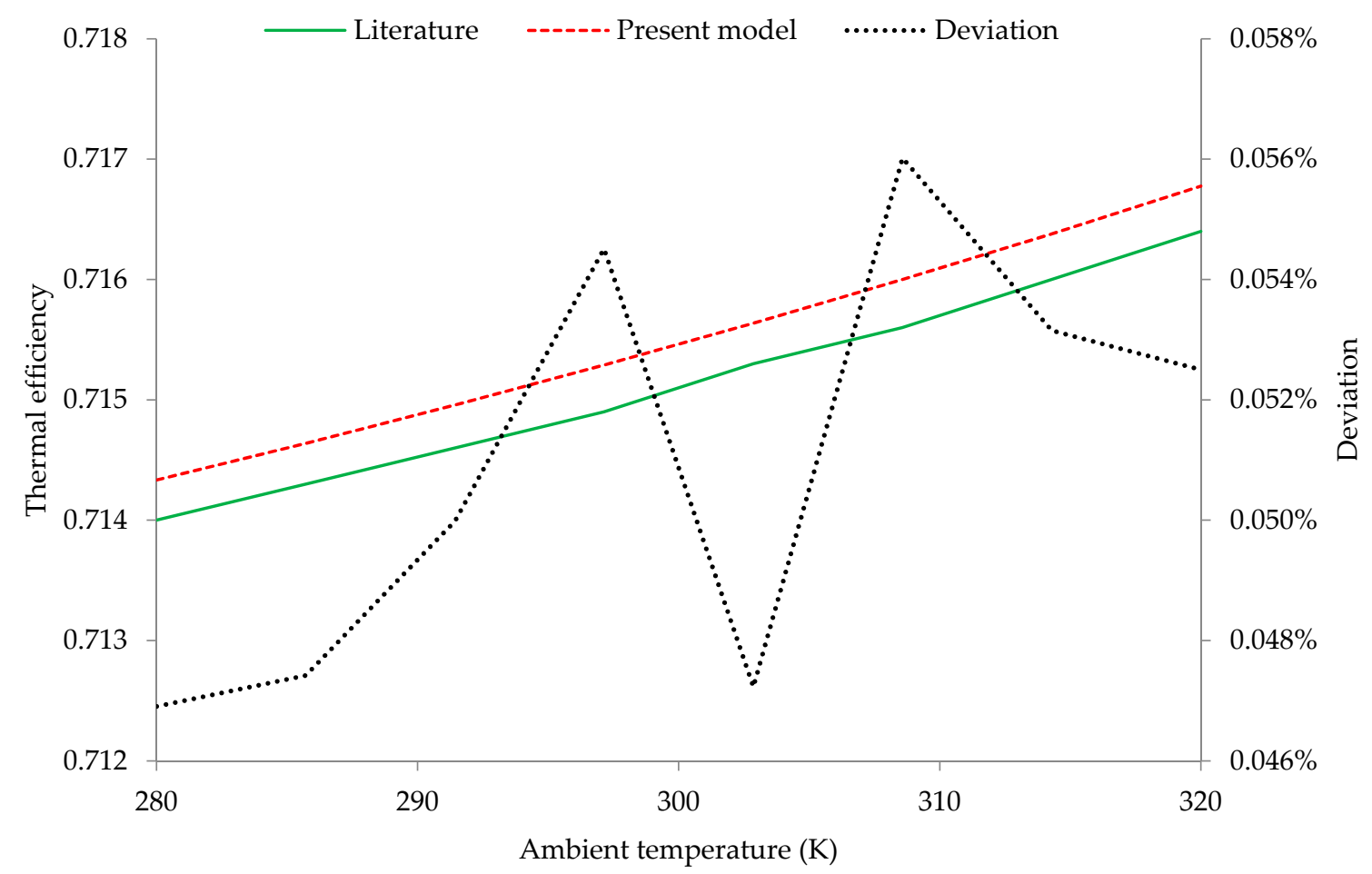

Figure 7. The impact of the ambient temperature on the model results.

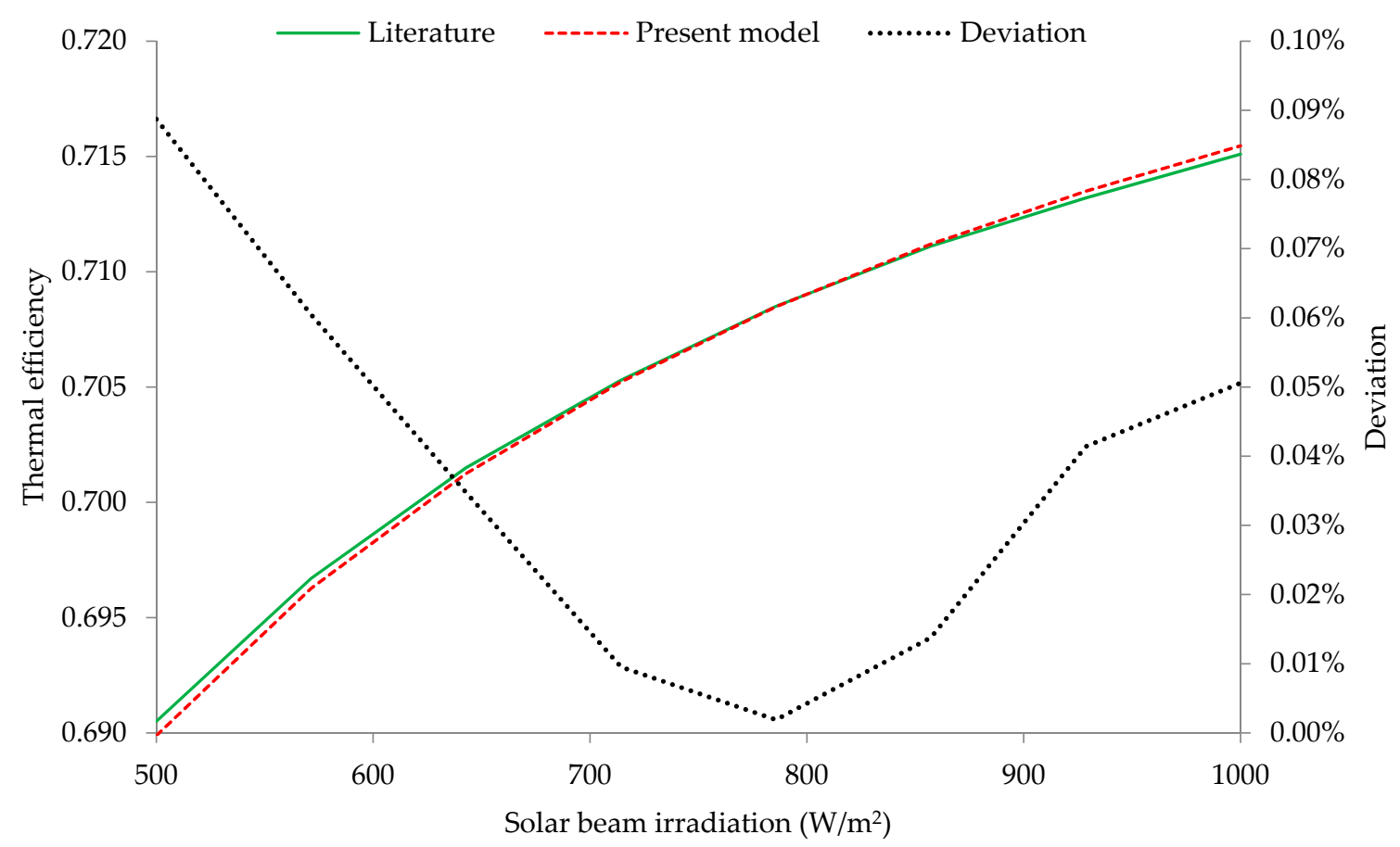

Figure 8. The impact of the solar beam irradiation on the model results. 


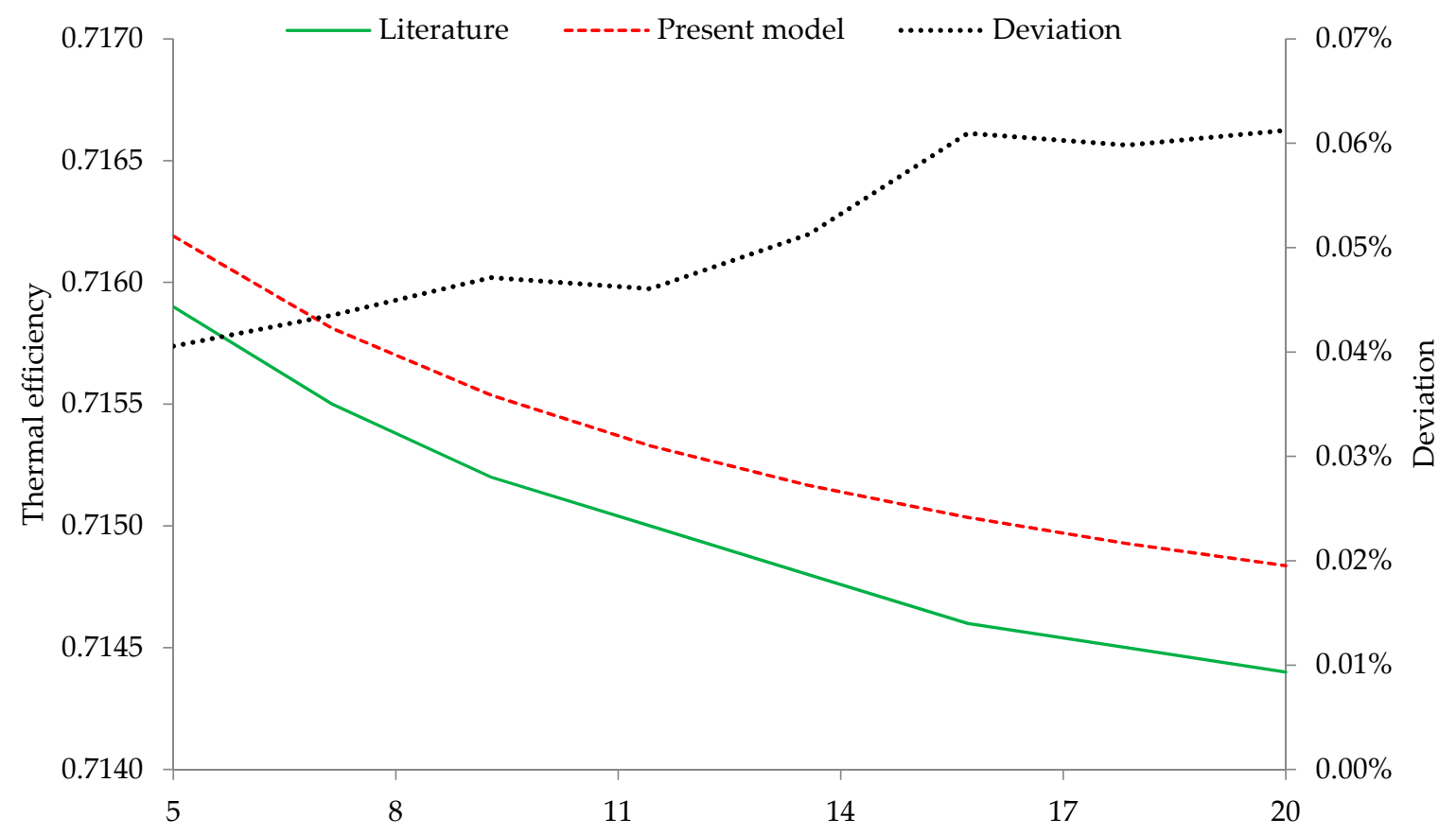

Figure 9. The impact of the heat transfer coefficient between cover and ambient on the model results.

\section{Conclusions}

In this work, an analytical modeling for the prediction of the thermal performance of a PTC is developed. This model is based on the determination of five parameters $\left(\mathrm{K}_{1}, \mathrm{~K}_{2}, \mathrm{~K}_{3}, \mathrm{~K}_{4}\right.$, and $\left.\mathrm{K}_{5}\right)$ which are used for the calculation of the thermal efficiency. Moreover, the calculations of the thermal losses, receiver temperature, cover temperature and the fluid outlet temperature are possible with simple and accurate formulas.

The developed model was compared with experimental results from Dudley et al. [5], as well as with the results of a developed model in EES, as it has been presented in Refs [19-25] with details. Finally, it is found that the thermal efficiency is calculated with extremely low deviations up to $0.2 \%$.

Moreover, it is found that the receiver and cover temperatures are also calculated with high accuracies. Only the thermal losses at low temperatures are estimated with lower precision. However, the difference is practically only a few Watts, the fact that makes the impact of these deviations to be negligible in the thermal efficiency calculation.

Furthermore, this model is tested with a sensitivity analysis for different inlet temperatures, flow rates, ambient temperatures, heat transfer coefficients between cover and ambient, as well as different solar beam irradiation rates. In all the cases, extremely low deviations are observed. The highest deviations are found only for low flow rates, but they were up to $0.5 \%$.

In summary, it can be said that the present model can be used for the quick and accurate calculation of the PTC performance. This model can be inserted in optimization algorithms for the simple and accurate design of PTC or solar thermal systems with PTC.

Acknowledgments: Evangelos Bellos would like to thank “Bodossaki Foundation" for its financial support.

Author Contributions: Evangelos Bellos and Christos Tzivanidis have the same contribution in all the parts of this work.

Conflicts of Interest: The authors declare no conflict of interest. 


\section{Nomenclature}

\begin{tabular}{|c|c|}
\hline A & Area, $\mathrm{m}^{2}$ \\
\hline $\mathrm{C}$ & Concentration ratio \\
\hline$c_{\mathrm{p}}$ & Specific heat capacity under constant pressure, J/ kg K \\
\hline $\mathrm{D}$ & Diameter, $\mathrm{m}$ \\
\hline $\mathrm{f}$ & Collector focal distance, $\mathrm{m}$ \\
\hline $\mathrm{G}_{\mathrm{b}}$ & Solar direct beam radiation, $\mathrm{W} / \mathrm{m}^{2}$ \\
\hline $\mathrm{h}$ & Heat transfer coefficient between fluid and absorber, $\mathrm{W} / \mathrm{m}^{2} \mathrm{~K}$ \\
\hline $\mathrm{h}_{\text {out }}$ & Heat transfer coefficient between cover and ambient, $\mathrm{W} / \mathrm{m}^{2} \mathrm{~K}$ \\
\hline k & Thermal conductivity, W/mK \\
\hline $\mathrm{K}$ & Incident angle modifier \\
\hline $\mathrm{K}_{1}$ & Coefficient of Equation (4), W/K \\
\hline $\mathrm{K}_{2}$ & Coefficient of Equation (11), W/K $\mathrm{K}^{4}$ \\
\hline $\mathrm{K}_{3}$ & Coefficient of Equation (17), W/K \\
\hline $\mathrm{K}_{4}$ & Coefficient of Equation (25) \\
\hline $\mathrm{K}_{5}$ & Coefficient of Equation (25), W/K \\
\hline $\mathrm{L}$ & Collector length, $\mathrm{m}$ \\
\hline $\mathrm{m}$ & Mass flow rate, $\mathrm{kg} / \mathrm{s}$ \\
\hline $\mathrm{Nu}$ & Nusselt number \\
\hline $\operatorname{Pr}$ & Prandtl number \\
\hline Q & Heat flux, W \\
\hline $\operatorname{Re}$ & Reynolds number \\
\hline $\mathrm{T}$ & Temperature, K \\
\hline $\mathrm{V}$ & Volumetric flow rate, $\mathrm{m}^{3} / \mathrm{s}$ \\
\hline W & Collector width, $\mathrm{m}$ \\
\hline \multicolumn{2}{|c|}{ Greek Symbols } \\
\hline$\alpha$ & Absorbance \\
\hline$\gamma$ & Intercept factor \\
\hline$\varepsilon_{\mathrm{c}}$ & Cover emittance \\
\hline$\varepsilon_{\mathrm{r}}$ & Absorber emittance \\
\hline$\varepsilon_{\mathrm{c}}{ }^{*}$ & Equivalent emittance \\
\hline$\eta$ & Efficiency \\
\hline$\theta$ & Incident angle, ${ }^{\circ}$ \\
\hline$\mu$ & Dynamic viscosity, Pa s \\
\hline$\rho$ & Density, $\mathrm{kg} / \mathrm{m}^{3}$ \\
\hline$\rho_{\mathrm{c}}$ & Reflectance \\
\hline$\sigma$ & Stefan-Boltzmann constant $\left[=5.67 \times 10^{-8} \mathrm{~W} / \mathrm{m}^{2} \mathrm{~K}^{4}\right]$ \\
\hline$\tau$ & Cover transmittance \\
\hline \multicolumn{2}{|c|}{ Subscripts and Superscripts } \\
\hline a & aperture \\
\hline am & ambient \\
\hline c & cover \\
\hline $\mathrm{ci}$ & inner cover \\
\hline co & outer cover \\
\hline $\mathrm{fm}$ & mean fluid \\
\hline in & inlet \\
\hline loss & losses \\
\hline $\max$ & maximum \\
\hline opt & optical \\
\hline out & outlet \\
\hline $\mathrm{r}$ & receiver \\
\hline ri & inner receiver \\
\hline ro & outer receiver \\
\hline $\mathrm{s}$ & solar \\
\hline th & thermal \\
\hline $\mathrm{u}$ & useful \\
\hline
\end{tabular}




\section{Abbreviations}

$\begin{array}{ll}\text { CFD } & \text { Computational Fluid Dynamics } \\ \text { EXP } & \text { Experimental } \\ \text { EES } & \text { Engineer Equator Solver } \\ \text { FEM } & \text { Finite Element Method } \\ \text { PTC } & \text { Parabolic trough collector }\end{array}$

\section{References}

1. Kumaresan, G.; Sudhakar, P.; Santosh, R.; Velraj, R. Experimental and numerical studies of thermal performance enhancement in the receiver part of solar parabolic trough collectors. Renew. Sustain. Energy Rev. 2017, 77, 1363-1374. [CrossRef]

2. Pavlovic, S.; Bellos, E.; Loni, R. Exergetic investigation of a solar dish collector with smooth and corrugated spiral absorber operating with various nanofluids. J. Clean. Prod. 2018, 174, 1147-1160. [CrossRef]

3. Bellos, E.; Tzivanidis, C.; Belessiotis, V. Daily performance of parabolic trough solar collectors. Sol. Energy 2017, 158, 663-678. [CrossRef]

4. Qu, W.; Wang, R.; Hong, H.; Sun, L.; Jin, G. Test of a solar parabolic trough collector with rotatable axis tracking. Appl. Energy 2017, 207, 7-17. [CrossRef]

5. Dudley, V.E.; Kolb, G.J.; Mahoney, A.R.; Mancini, T.R.; Matthews, C.W.; Sloan, M.; Kearney, D. Test Results: SEGS LS2 Solar Collector; Report of Sandia National Laboratories, SAN94-1884; Sandia National Laboratories: Livermore, CA, USA, 1994.

6. Sallaberry, F.; Valenzuela, L.; Palacin, L.G. On-site parabolic-trough collector testing in solar thermal power plants: Experimental validation of a new approach developed for the IEC 62862-3-2 standard. Sol. Energy 2017, 155, 398-409. [CrossRef]

7. Wang, R.; Sun, J.; Hong, H.; Liu, Q. An on-site test method for thermal and optical performances of parabolic-trough loop for utility-scale concentrating solar power plant. Sol. Energy 2017, 153, 142-152. [CrossRef]

8. Chafie, M.; Aissa, M.F.B.; Guizani, A. Energetic end exergetic performance of a parabolic trough collector receiver: An experimental study. J. Clean. Prod. 2018, 171, 285-296. [CrossRef]

9. Wu, Z.; Li, S.; Yuan, G.; Lei, D.; Wang, Z. Three-dimensional numerical study of heat transfer characteristics of parabolic trough receiver. Appl. Energy 2014, 113, 902-911. [CrossRef]

10. Mwesigye, A.; Huan, Z.; Meyer, J.P. Thermodynamic optimisation of the performance of a parabolic trough receiver using synthetic oil-Al2O3 nanofluid. Appl. Energy 2015, 156, 398-412. [CrossRef]

11. Mwesigye, A.; Huan, Z.; Meyer, J.P. Thermal performance of a receiver tube for a high concentration ratio parabolic trough system and potential for improved performance with Syltherm 800-CuO nanofluid. In Proceedings of the ASME 2015 International Mechanical Engineering Congress and Exposition IMECE2015, Houston, TX, USA, 13-19 November 2015.

12. Mwesigye, A.; Huan, Z. Thermodynamic analysis and optimization of fully developed turbulent forced convection in a circular tube with water- $\mathrm{Al}_{2} \mathrm{O}_{3}$ nanofluid. Int. J. Heat Mass Transf. 2015, 89, 694-706. [CrossRef]

13. Ghasemi, S.E.; Ranjbar, A.A. Thermal performance analysis of solar parabolic trough collector using nanofluid as working fluid: A CFD modelling study. J. Mol. Liq. 2016, 222, 159-166. [CrossRef]

14. Ghasemi, S.E.; Ranjbar, A.A. Effect of using nanofluids on efficiency of parabolic trough collectors in solar thermal electric power plants. Int. J. Hydrogen Energy 2017, 42, 21626-21634. [CrossRef]

15. Tzivanidis, C.; Bellos, E.; Korres, D.; Antonopoulos, K.A.; Mitsopoulos, G. Thermal and optical efficiency investigation of a parabolic trough collector. Case Stud. Therm. Eng. 2015, 6, 226-237. [CrossRef]

16. Bellos, E.; Tzivanidis, C.; Antonopoulos, K.A.; Gkinis, G. Thermal enhancement of solar parabolic trough collectors by using nanofluids and converging-diverging absorber tube. Renew. Energy 2016, 94, 213-222. [CrossRef]

17. Bellos, E.; Tzivanidis, C.; Tsimpoukis, D. Thermal, hydraulic and exergetic evaluation of a parabolic trough collector operating with thermal oil and molten salt based nanofluids. Energy Convers. Manag. 2018, 156, 388-402. [CrossRef]

18. Forristall, R. Heat Transfer Analysis and Modeling of a Parabolic Trough Solar Receiver Implemented in Engineering Equation Solver; National Renewable Energy Laboratory (NREL): Lakewood, CO, USA, 2003. 
19. Bellos, E.; Tzivanidis, C.; Antonopoulos, K.A.; Daniil, I. The use of gas working fluids in parabolic trough collectors-An energetic and exergetic analysis. Appl. Therm. Eng. 2016, 109, 1-14. [CrossRef]

20. Bellos, E.; Tzivanidis, C.; Antonopoulos, K.A. A detailed working fluid investigation for solar parabolic trough collectors. Appl. Therm. Eng. 2017, 114, 374-386. [CrossRef]

21. Bellos, E.; Tzivanidis, C. Parametric investigation of nanofluids utilization in parabolic trough collectors. Therm. Sci. Eng. Prog. 2017, 2, 71-79. [CrossRef]

22. Bellos, E.; Tzivanidis, C. A detailed exergetic analysis of parabolic trough collectors. Energy Convers. Manag. 2017, 149, 275-292. [CrossRef]

23. Bellos, E.; Tzivanidis, C. Parametric investigation of supercritical carbon dioxide utilization in parabolic trough collectors. Appl. Therm. Eng. 2017, 127, 736-747. [CrossRef]

24. Bellos, E.; Tzivanidis, C. Thermal analysis of parabolic trough collector operating with mono and hybrid nanofluids. Sustain. Energy Technol. Assess. 2017. [CrossRef]

25. Bellos, E.; Tzivanidis, C. Assessment of the thermal enhancement methods in parabolic trough collectors. Int. J. Energy Environ. Eng. 2018, 9, 59-70. [CrossRef]

26. Kalogirou, S.A. A detailed thermal model of a parabolic trough collector receiver. Energy 2012, 48, $298-306$. [CrossRef]

27. Behar, O.; Khellaf, A.; Mohammedi, K. A novel parabolic trough solar collector model—Validation with experimental data and comparison to Engineering Equation Solver (EES). Energy Convers. Manag. 2015, 106, 268-281. [CrossRef]

28. Guo, J.; Huai, X.; Liu, Z. Performance investigation of parabolic trough solar receiver. Appl. Therm. Eng. 2016, 95, 357-364. [CrossRef]

29. Padilla, R.V.; Demirkaya, G.; Goswami, D.Y.; Stefanakos, E.; Rahman, M.M. Heat transfer analysis of parabolic trough solar receiver. Appl. Energy 2011, 88, 5097-5110. [CrossRef]

30. Cheng, Z.-D.; He, Y.-L.; Qiu, Y. A detailed nonuniform thermal model of a parabolic trough solar receiver with two halves and two inactive ends. Renew. Energy 2015, 74, 139-147. [CrossRef]

31. Liang, H.; You, S.; Zhang, H. Comparison of different heat transfer models for parabolic trough solar collectors. Appl. Energy 2015, 148, 105-114. [CrossRef]

32. Jeter, S.M. Analytical determination of the optical performance of practical parabolic trough collectors from design data. Sol. Energy 1987, 39, 11-21. [CrossRef]

33. Khanna, S.; Kedare, S.B.; Singh, S. Analytical expression for circumferential and axial distribution of absorbed flux on a bent absorber tube of solar parabolic trough concentrator. Sol. Energy 2013, 92, 26-40. [CrossRef]

34. Fraidenraich, N.; Oliveira, C.; da Cunha, A.F.V.; Gordon, J.M.; Vilela, O.C. Analytical modeling of direct steam generation solar power plants. Sol. Energy 2016, 98, 511-522. [CrossRef]

35. Eck, M.; Feldhoff, J.F.; Uhlig, R. Thermal modelling and simulation of parabolic trough receiver tubes. In Proceedings of the ASME 2010 4th International Conference on Energy Sustainability, Phoenix, AZ, USA, 17-22 May 2010.

36. Eck, M.; Steinmann, W.-D. Modelling and Design of Direct Solar Steam Generating Collector Fields. J. Sol. Energy Eng. 2005, 127, 371-380. [CrossRef]

37. Conrado, L.S.; Rodriguez-Pulido, A.; Calderón, G. Thermal performance of parabolic trough solar collectors. Renew. Sustain. Energy Rev. 2017, 67, 1345-1359. [CrossRef]

38. Sandeep, H.M.; Arunachala, U.C. Solar parabolic trough collectors: A review on heat transfer augmentation techniques. Renew. Sustain. Energy Rev. 2017, 69, 1218-1231. [CrossRef]

39. Fuqiang, W.; Ziming, C.; Jianyu, T.; Yuan, Y.; Yong, S.; Linhua, L. Progress in concentrated solar power technology with parabolic trough collector system: A comprehensive review. Renew. Sustain. Energy Rev. 2017, 79, 1314-1328. [CrossRef]

40. Lienhard, J.H. A Heat Tranfer Textbook, 4th ed.; Philogiston Press: Cambridge, MA, USA, 2012; pp. 354-360.

41. Silicon Heat Transfer Fluid. Available online: http://www.loikitsdistribution.com/files/syltherm-800technical-data-sheet.pdf (accessed on 15 January 2018).

(C) 2018 by the authors. Licensee MDPI, Basel, Switzerland. This article is an open access article distributed under the terms and conditions of the Creative Commons Attribution (CC BY) license (http:// creativecommons.org/licenses/by/4.0/). 